\title{
Effect of Daily Communication Behaviors on Cognitive and Language Abilities of the Elderly
}

\author{
Soo Ryon Kim', HyangHee Kim²,3 \\ 'Department of Speech and Language Therapy, College of Health Sciences, Catholic University of Pusan, Busan, Korea \\ ${ }^{2}$ Graduate Program in Speech and Language Pathology, Yonsei University, Seoul, Korea \\ ${ }^{3}$ Department and Research Institute of Rehabilitation Medicine, Yonsei University College of Medicine, Seoul, Korea
}

\begin{abstract}
Purpose: The International Classification of Functioning, Disability, and Health can be utilized to measure individual health. Although 'activity' is one of the components of health, no studies have investigated the frequency of participation of the elderly in daily communication activities, such as talking, reading, and writing. We examined the daily communication behaviors of normal elderly subjects and their effects on cognitive and language test performance. Methods: Normal elderly subjects $(n=456)$ over 60 years old completed a questionnaire on how often they thought that they talked/read/wrote in their daily lives. Also, they were administered the Korean Mini-Mental State Examination, Controlled Oral Word Association Test, Short Form of the Korean version-the Boston Naming Test, and Sentence Comprehension Test. Results: About $50 \%$ of the participants reported that they seldom talked, read, and/or wrote daily. The more frequently that the participants reported daily talking, reading and writing, the better they performed on cognitive and/or language tests. Daily writing influenced the test results the most, which suggested that writing behavior was closely related to all four cognitive/ language tests. Conclusion: These results suggested that daily active communication behaviors play major roles in the cognitive and language abilities of the elderly.
\end{abstract}

Key Words: Elderly, Communication behaviors, Writing, Cognition, Language.

Received: April 25, 2017 / Revised: June 26, 2017 / Accepted: July 10, 2017

Correspondence: HyangHee Kim, Graduate Program in Speech and Language Pathology, Department and Research Institute of Rehabilitation Medicine, Yonsei University College of Medicine, 50 Yonsei-ro, Seodaemun-gu, Seoul 03722, Korea

Tel: +82-2-2228-3900 / Fax: +82-2-2227-7984 / E-mail: h.kim@yonsei.ac.kr

\section{INTRODUCTION}

Demographic factors, such as age, sex, and ethnicity (Goral et al., 2007; Henderson et al., 1998; MacKay \& Connor, 2001; Randolph et al., 1999); socioeconomic factors, such as income, education, and occupation (Jorm et al., 1998; Peltzer \& Phaswana-Mafuya, 2012; Proust-Lima et al., 2008); health-related factors, such as hypertension and diabetes mellitus (Brady et al., 2005; Kuo et al., 2005; Raz et al., 2003); and social environmental factors, such as interactions with and emotional support from others (Freidl et al., 1996; Seeman et al., 2001), have been shown to affect the cognitive and language abilities of normal elderly subjects.

The International Classification of Functioning, Disability and Health (World Health Organization, 2001), which is used to measure individual health and function, contains three components: body functions and structure, activities and participation, and contextual factors, including personal factors and en- vironmental factors. Demographic and socioeconomic factors are examined with the personal factors scale, while health-related factors are assessed with the body functions and structure scale. In addition, social environment is investigated with the environmental factors scale. Although a number of studies have examined the effects of these factors on cognitive and language abilities, few studies have examined their effects on the communication behaviors of normal elderly subjects with the activities and participation scale.

Three basic communication behaviors, talking, reading, and writing, delineate functional communication. Previous studies of the talking behaviors of the elderly have presented the characteristics of the talking behaviors (e.g., topic shift in discourse) and/or methods for facilitating conversation with the oldest elderly or demented patients (Gentry \& Fisher, 2007; Gibb \& O’Brien, 1990). Schneider \& Lichtenberg (2011) have reported that reading ability is significantly associated with performance on the Trail Making, Controlled Oral Word Association, Animal 
Naming, Digit Span, and Stroop tests. In a study that followed the subjects for 8 years, over $60 \%$ of the elderly reported that they read every day at both 70 and 78 years of age, and daily reading significantly reduced the hazard ratio for mortality over the 8-year period in men (Jacobs et al., 2008). Most studies on the writing activities of the elderly have focused on literacy and its effects on health and mortality (Mark, 2009).

To the best of our knowledge, no studies to date have reported how often the elderly think they participate in daily communication situations where they talk, read, or write, and whether the frequencies of these communication behaviors affect cognitive and language abilities. The current study classified the participants into three communication groups based on the questionnaire results and examined whether the groups had differences in the performance of objective cognitive and language tests, including the Korean Mini-Mental State Examination (K-MMSE), Controlled Oral Word Association Test (COWAT), the Short Form-Korean version-the Boston Naming Test (K-BNT- 15), and Sentence Comprehension Test.

\section{MATERIALS AND METHODS}

\section{Participants}

The participants were 456 normal elderly subjects over 60 years old who were recruited from Korean communities. They had no neurological or psychiatric histories, and their MMSE scores were normal based on their age and education years. This study complied with all applicable ethical rules and regulations and was approved by the Institutional Review Board (IRB\#: 1-20110061).

Because the questionnaires used in this study included reading and writing activities, a literacy test consisting of four reading and four writing items was administered. The reading items required the subjects to answer two questions after reading a short phrase and another two questions after reading functional material (e.g., a prescription). The writing items required the participants to write their name, a dictated word, one simple sentence, and a three-sentence composition.

Based on the literacy test scores, the participants were divided into literate or illiterate groups. Two points separated the scores of the literate and illiterate groups because two points or less indicated no or very low literacy and incompetence in daily functional literacy activities. Table 1 shows the demographic characteristics of the subjects in the groups.

\section{Materials}

Daily communication behavior questionnaire

The questionnaire used to assess daily communication consisted of the following three questions: 1) how often do you think you are talking in everyday life (TALKING); 2) how often do you think you are reading in everyday life (READING); and 3) how often do you think you are writing in everyday life (WRITING). The subjects answered SELDOM, SOMETIMES, or FREQUENTLY.

To investigate the effects of daily communication behaviors on the subjects' performances on cognitive and language tests, the participants were classified an INACTIVE communication group if they answered SELDOM on the daily communication questionnaire, SEMIACTIVE communication group if they answered SOMETIMES on the questionnaire, or ACTIVE communication group if they answered FREQUENTLY.

\section{Cognitive and language tests}

We administered the K-MMSE, COWAT, K-BNT-15, and the Sentence Comprehension Test. The K-MMSE screens for general cognitive impairments in orientation, memory, attention, language, and/or visuospatial ability. The COWAT requires the subject to say as many words as possible in a category (i.e., animal) for a given period, which is usually one minute. However, in this study, the period was 30 seconds because significant differences between subjects have been found previously with the 30-second period (Kim et al., 2011; Lee et al., 2015). The COWAT is sensitive to impairments in the prefrontal lobe, which is vulnerable in aging (Rodríguez-Aranda \& Sundet, 2006). The K-BNT-15, which is a confrontation naming test in which the subjects name 15 objects, was developed in the short form based on Item Response Theory (Kim \& Kim, 2013). Multidimensional scoring systems were adopted to quantify the subjects' responses. The responses on the K-BNT-15 were scored $0,1,2$, or 3 for incorrect, self-corrected, delayed, or correct, respectively. The Sentence

Table 1. Demographic information of the participants

\begin{tabular}{lccccc}
\hline Groups & No & Gender $(\mathrm{M}: \mathrm{F})$ & Age $($ mean $\pm \mathrm{SD})$ & Formal education years $(\mathrm{mean} \pm \mathrm{SD})$ & MMSE $(\mathrm{mean} \pm \mathrm{SD})$ \\
\hline Literate & 383 & $118: 265$ & $73.75 \pm 6.04$ & $8.03 \pm 3.81$ & $25.81 \pm 3.03$ \\
Illiterate & 73 & $7: 66$ & $77.58 \pm 6.64$ & $0.96 \pm 2.13$ & $19.82 \pm 3.49$ \\
Total & 456 & $125: 331$ & $74.34 \pm 6.27$ & $6.97 \pm 4.41$ & $24.90 \pm 3.76$ \\
\hline
\end{tabular}

MMSE: Mini-Mental State Examination, SD: standard deviation 

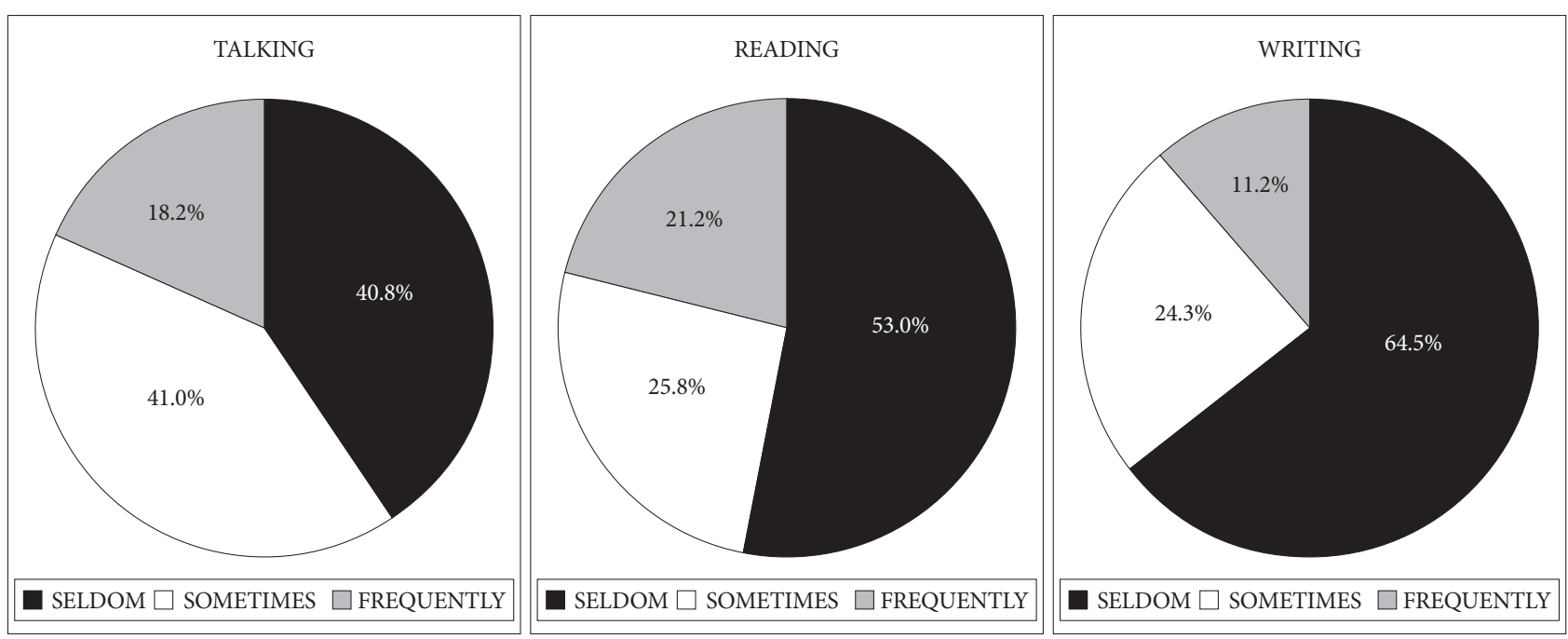

Figure 1. The elderly's self-reporting frequencies of the daily TALKING, READING, and WRITING behaviors.

Comprehension Test consists of 12 sentences with simple or complex grammar. After listening to a sentence, the participant selects one of four pictures.

\section{Statistical analysis}

We analyzed the cognitive and language performances of the subjects in the INACTIVE, SEMIACTIVE, and ACTIVE groups with a one-way analysis of covariance (ANCOVA) after adjusting for age and/or education. The TALKING behaviors of the literate and illiterate groups were compared, while the READING and WRITING behaviors were analyzed in only the literate group. Post hoc analyses were conducted to identify differences among the three groups. All statistical analyses were performed with SPSS software (version 18.0 for Windows; IBM Corporation, Armonk, NY, USA), and $p$ values less than 0.05 were considered significant.

\section{RESULTS}

\section{Daily communication behaviors}

For daily TALKING, $40.8 \%$ (186/456) of the participants answered SELDOM (i.e., they reported that they seldom talked daily), 41.0\% (187/456) responded SOMETIMES, and 18.2\% (83/456) replied FREQUENTLY. For daily READING behaviors, $53.0 \%$ (203/383), 25.8\% (99/383), and 21.2\% (81/383) of the literate elderly responded SELDOM, SOMETIMES, and FREQUENTLY, respectively. Finally, for daily WRITING behaviors, 64.5\% (247/383), 24.3\% (93/383), 11.2\% (43/383) answered SELDOM, SOMETIMES, and FREQUENTLY, respectively. Figure 1 shows the elderly subjects' self-reporting frequencies
Table 2. Comparison of MMSE among the literate elderly groups according to talking behaviors

\begin{tabular}{lcccc}
\hline \multicolumn{1}{c}{ Talking groups } & $\begin{array}{c}\text { MMSE } \\
(\text { mean } \pm \text { SD) }\end{array}$ & F & $p$ & Scheffé \\
\hline INACTIVE $(\mathrm{a})(\mathrm{n}=203)$ & $25.35 \pm 1.29$ & 16.701 & 0.000 & $\mathrm{a}<\mathrm{b}^{\dagger}$ \\
SEMI-ACTIVE $(\mathrm{b})(\mathrm{n}=99)$ & $26.21 \pm 1.30$ & & & $\mathrm{a}<\mathrm{c}^{*}$ \\
ACTIVE $(\mathrm{c})(\mathrm{n}=81)$ & $25.90 \pm 1.36$ & & \\
\hline${ }^{*} p<0.01,{ }^{\dagger} p<0.001$. MMSE: Mini-Mental State Examination, SD: \\
standard deviation
\end{tabular}

on their daily TALKING, READING, and WRITING behaviors.

Cognitive and language test performance

Talking behaviors

The literate elderly

In the literate elderly, ANCOVAs with the covariate(s) of age and/or education years showed significant differences in the MMSE $(p<0.001)$ and COWAT $(p<0.001)$ scores and no differences in the K-BNT-15 and Sentence Comprehension Test scores. Post hoc analyses indicated that the INACTIVE communication group had significantly decreased MMSE (Table 2) and COWAT test scores (Table 3) compared with the scores of the SEMIACTIVE and ACTIVE communication groups.

The illiterate elderly

Based on the results of a multivariate ANOVA, age was adjusted in the ANCOVAs of the MMSE and COWAT scores in the illiterate elderly subjects. The ANCOVAs showed a significant difference only in the MMSE scores $(p<0.001)$ and no dif- 
ferences in the COWAT, K-BNT-15, and Sentence Comprehension Test. The post hoc analyses indicated that the MMSE score of the INACTIVE communication group differed from those of the SEMIACTIVE and ACTIVE groups (Table 4).

\section{Reading behaviors}

Age and education years were adjusted in the ANCOVAs of the MMSE and K-BNT-15 scores, while only education years were adjusted in the ANCOVAs of the COWAT and the Sentence Comprehension Test scores. The ANCOVAs showed a significant difference in the K-BNT-15 scores $(p<0.001)$ and no differences in the other test scores. The post hoc analysis indicated that the K-BNT-15 scores of the INACTIVE communication group differed significantly from those of the SEMIACTIVE and ACTIVE groups (Table 5).

\section{Writing behaviors}

Education years were adjusted for in the analyses of the MMSE and COWAT scores. The ANCOVA showed significant differences according to the frequencies of daily writing behaviors in the scores of all tests, including the MMSE $(p<0.001)$ (Table 6),

Table 3. Comparison of COWAT among the literate elderly groups according to talking behaviors

\begin{tabular}{lcccc}
\hline \multicolumn{1}{c}{ Talking groups } & $\begin{array}{c}\text { COWAT } \\
(\text { mean } \pm \text { SD) }\end{array}$ & F & $p$ & Scheffé \\
\hline INACTIVE $(\mathrm{a})(\mathrm{n}=203)$ & $8.90 \pm 0.84$ & 44.255 & 0.000 & $\mathrm{a}<\mathrm{b}, \mathrm{c}^{*}$ \\
SEMI-ACTIVE $(\mathrm{b})(\mathrm{n}=99)$ & $9.74 \pm 0.85$ & & & \\
ACTIVE $(\mathrm{c})(\mathrm{n}=81)$ & $9.87 \pm 0.90$ & & \\
\hline $\begin{array}{l}{ }^{*} p<0.001 . \text { COWAT: Controlled Oral Word Association Test, SD: } \\
\text { standard deviation }\end{array}$
\end{tabular}

Table 4. Comparison of MMSE among the illiterate elderly groups according to talking behaviors

\begin{tabular}{|c|c|c|c|c|}
\hline Talking groups & $\begin{array}{c}\text { MMSE } \\
(\text { mean } \pm \text { SD })\end{array}$ & $\mathrm{F}$ & $p$ & Scheffé \\
\hline$\overline{\text { INACTIVE }(\mathrm{a})(\mathrm{n}=44)}$ & $19.03 \pm 3.48$ & 3.174 & 0.000 & $\mathrm{a}<\mathrm{b}, \mathrm{c}^{*}$ \\
\hline SEMI-ACTIVE $(\mathrm{b})(\mathrm{n}=18)$ & $20.82 \pm 3.76$ & & & \\
\hline $\operatorname{ACTIVE}(\mathrm{c})(\mathrm{n}=11)$ & $21.60 \pm 2.71$ & & & \\
\hline
\end{tabular}

Table 5. Comparison of BNT among the literate elderly groups according to reading behaviors

\begin{tabular}{lcccc}
\hline \multicolumn{1}{c}{ Reading groups } & $\begin{array}{c}\text { BNT } \\
(\text { mean } \pm \text { SD) }\end{array}$ & F & $p$ & Scheffé \\
\hline INACTIVE (a) $(\mathrm{n}=203)$ & $28.54 \pm 4.39$ & 2.996 & 0.000 & $\mathrm{a}<\mathrm{b}, \mathrm{c}^{*}$ \\
SEMI-ACTIVE $(\mathrm{b})(\mathrm{n}=99)$ & $31.79 \pm 4.74$ & & & \\
ACTIVE (c) $(\mathrm{n}=81)$ & $32.36 \pm 5.24$ & & & \\
\hline
\end{tabular}

${ }^{*} p<0.001$. BNT: Boston Naming Test, SD: standard deviation

COWAT $(p<0.001)$ (Table 7), K-BNT-15 ( $p<0.001$ ) (Table 8), and Sentence Comprehension Test $(p<0.001)$ (Table 9). Post hoc analyses indicated that all of the scores of the INACTIVE communication group differed significantly from those of the SEMIACTIVE and ACTIVE groups.

\section{DISCUSSIONS}

The purpose of this study was to identify whether there were differences in cognitive and language performances among active, semi-active, and inactive communication elderly groups classified on the basis of their perceived communication fre-

Table 6. Comparison of MMSE among the literate elderly groups according to writing behaviors

\begin{tabular}{|c|c|c|c|c|}
\hline Writing groups & $\begin{array}{c}\text { MMSE } \\
(\text { mean } \pm \text { SD })\end{array}$ & $\mathrm{F}$ & $p$ & Scheffé \\
\hline$\overline{\text { INACTIVE }(\mathrm{a})(\mathrm{n}=247)}$ & $25.10 \pm 0.88$ & 222.416 & 0.000 & $a<b, c^{*}$ \\
\hline SEMI-ACTIVE $(b)(n=93)$ & $27.10 \pm 0.85$ & & & \\
\hline $\operatorname{ACTIVE}(\mathrm{c})(\mathrm{n}=43)$ & $27.23 \pm 0.84$ & & & \\
\hline
\end{tabular}

Table 7. Comparison of COWAT among the literate elderly groups according to writing behaviors

\begin{tabular}{lcccc}
\hline \multicolumn{1}{c}{ Writing groups } & $\begin{array}{c}\text { COWAT } \\
(\text { mean } \pm \text { SD })\end{array}$ & F & $p$ & Scheffé \\
\hline INACTIVE (a) $(\mathrm{n}=247)$ & $8.97 \pm 0.48$ & 307.359 & 0.000 & $\mathrm{a}<\mathrm{b}, \mathrm{c}^{*}$ \\
SEMI-ACTIVE $(\mathrm{b})(\mathrm{n}=93)$ & $10.35 \pm 0.47$ & & \\
ACTIVE (c) $(\mathrm{n}=43)$ & $10.13 \pm 0.46$ & & \\
\hline
\end{tabular}

${ }^{*} p<0.001$. COWAT: Controlled Oral Word Association Test, SD: standard deviation

Table 8. Comparison of BNT among the literate elderly groups according to writing behaviors

\begin{tabular}{lcccc}
\hline \multicolumn{1}{c}{ Writing groups } & $\begin{array}{c}\text { BNT } \\
(\text { mean } \pm \text { SD })\end{array}$ & F & $p$ & Scheffé \\
\hline INACTIVE (a) $(\mathrm{n}=247)$ & $28.53 \pm 4.52$ & 46.382 & 0.000 & $\mathrm{a}<\mathrm{b}, \mathrm{c}^{*}$ \\
SEMI-ACTIVE $(\mathrm{b})(\mathrm{n}=93)$ & $33.13 \pm 4.52$ & & & \\
ACTIVE (c) $(\mathrm{n}=43)$ & $33.61 \pm 3.88$ & & & \\
\hline
\end{tabular}

${ }^{*} p<0.001$. BNT: Boston Naming Test, SD: standard deviation

Table 9. Comparison of Sentence Comprehension Test among the literate elderly groups according to writing behaviors

\begin{tabular}{|c|c|c|c|c|}
\hline Writing groups & $\begin{array}{l}\text { Sent. comp. } \\
(\text { mean } \pm \text { SD })\end{array}$ & $\mathrm{F}$ & $p$ & Scheffé \\
\hline INACTIVE (a) $(\mathrm{n}=247)$ & $17.88 \pm 1.24$ & 45.685 & 0.000 & $\mathrm{a}<\mathrm{b}, \mathrm{c}^{*}$ \\
\hline SEMI-ACTIVE $(b)(n=93)$ & $19.00 \pm 1.27$ & & & \\
\hline $\operatorname{ACTIVE}(\mathrm{c})(\mathrm{n}=43)$ & $19.46 \pm 1.21$ & & & \\
\hline
\end{tabular}


quencies. The study results indicated that both the illiterate and literate elderly subjects who seldom engaged in daily talking behaviors performed worse on cognitive and/or language tests compared with those subjects who actively engaged in daily talking. In addition, the literate elderly subjects who seldom performed daily reading and writing behaviors exhibited decreased cognitive and language abilities. These results showed that the frequencies of performing all three of the communication behaviors (talking, reading, and writing) affected cognitive and/or language performance. Therefore, the more often that the participants talked, the better they performed on general cognitive tests (i.e., MMSE) and/or verbal fluency tests (i.e., COWAT). Frequent reading activities were related to increased confrontation naming ability (i.e., K-BNT-15 score). Frequent writing activities resulted in better performances on general cognition, verbal fluency, confrontation naming, and Sentence Comprehension Tests. These results suggested that the daily performance of writing behaviors most affected cognitive and language performance.

Writing is a complex psychomotor activity that requires adequate cognitive-linguistic skills and motor abilities. With intact linguistic knowledge and sufficient memory abilities, writing is accomplished through automated skilled movements and visuomotor cooperation (Longstaff \& Heath, 1997). Torrance et al. (2007) have reported that various lower and higher cognitive processes are coordinated during writing. These cognitive processes include motor executive function, spelling, pausing behavior, verbal and visual working memory, and content generation and strategies. Writing is more demanding and complex than talking and reading. Therefore, daily writing activities result in extensive practice in the general linguistic, cognitive, and motoric domains.

A large percentage of the elderly reported that they seldom talked, read, and/or wrote in their daily lives. Specifically, $41 \%$ of the elderly seldom talked, $53 \%$ of them seldom read, and $65 \%$ of them seldom wrote. Many factors might have contributed to these results. First, the absence of conversation partners results in seldom conversation opportunities. The number of elderly people who are alone has doubled compared to 10 years ago. Furthermore, this number was estimated in 2012 to increase to $20 \%$ of all seniors by 2015 (Statistics of Korea, 2012). Second, poor health conditions, such as suffering from a disease like rheumatoid arthritis, prevent the elderly visiting senior community centers or their relatives for social conversation. Third, the high percentage of illiteracy in the Korean elderly precludes reading and writing activities. The illiteracy rate is approximately $20 \%$ of the elderly over 70 in Korea (Korean Educational De- velopment Institute, 2002). Finally, even for the literate elderly, reading and writing can be challenging because of presbyopia (farsightedness) (Burda, 2011). These unfavorable conditions contribute to rare opportunities for communication in daily life. Infrequent communication behavior negatively affects cognitive and language performance. Therefore, elderly people should make frequent attempts to talk, read, and write actively in their daily lives. For example, the elderly should make more effort to participate in communication situations with others, such as frequently visiting senior centers and acquaintances. In addition, even when elderly subjects are alone, they should try to do communication activities, such as committing to a daily speaking schedule, memorizing vocabulary aloud, reciting poems, reading books/newspapers/the Bible, writing in a diary daily, and writing their schedule in a calendar.

This study is limited in that we classified the communication groups based on self-reporting frequencies on daily communication behaviors. These findings of the study warrant subsequent studies including specific and comprehensive data on communication behaviors of elderly people. The data can be further developed as objective classification criteria of subjects. Nonetheless, this study is noteworthy in that elderly people should participate in daily communication situations actively to increase their cognitive and language abilities for successful aging.

\section{REFERENCES}

Brady, C. B., Spiro III, A., \& Gaziano, J. M. (2005). Effects of age and hypertension status on cognition: The veterans affairs normative aging study. Neuropsychology, 19(6), 770-777.

Burda, A. N. (2011). Communication and Swallowing Changes in Healthy Aging Adults. Sudbury, MA: Jones \& Bartlett Learning.

Freidl, W., Schmidt, R., Stronegger, W. J., Irmler, A., Reinhart, B., \& Koch, M. (1996). Mini Mental State Examination: Influence of sociodemographic, environmental and behavioral factors, and vascular risk factors. Journal of Clinical Epidemiology, 49(1), 73-78.

Gentry, R. A. \& Fisher, J. E. (2007). Facilitating conversation in elderly persons with Alzheimer's disease. Clinical Gerontologist, 31(2), 77-98.

Gibb, H. \& O’Brien, B. (1990). Jokes and reassurance are not enough: Ways in which nurses relate through conversation with elderly clients. Journal of Advanced Nursing, 15(12), 1389-1401.

Goral, M., Spiro III, A., Albert, M. L., Obler, L. K., \& Connor, L. T. (2007). Change in lexical retrieval skills in adulthood. The Mental Lexicon, 2(2), 215-240.

Henderson, L. W., Frank, E. M., Pigatt, T., Abramson, R. K., \& Houston, M. (1998). Race, gender, and educational level effects on Boston Naming Test scores. Aphasiology, 12(10), 901-911.

Jacobs, J. M., Hammerman-Rozenberg, R., Cohen, A., \& Stessman, J. (2008). Reading daily predicts reduced mortality among men from a cohort of community-dwelling 70-year-olds. The Journals of Gerontology Series B: Psychological Sciences and Social Sciences, 63(2), S73-S80.

Jorm, A. F., Rodgers, B., Henderson, A. S., Korten, A. E., Jacomb, P. A., Christensen, H., et al. (1998). Occupation type as a predictor of cognitive decline and dementia in old age. Age and Ageing, 27(4), 477-483.

Kim, H., Kim, J., Kim, D. Y., \& Heo, J. (2011). Differentiating between apha- 
sic and nonaphasic stroke patients using semantic verbal fluency measures with administration time of 30 seconds. European Neurology, 65(2), 113-117.

Kim, H. \& Kim, S. R. (2013). Development of short form of the Korean version-the Boston Naming Test (K-BNT-15) based on item response theory. The Journal of the Korea Contents Association, 13(12), 321-327.

Lee, S. H., Kim, H., Kim, J., Yoon, J. H., \& Kim, S. R. (2015). Initial phase performance in a 30-s verbal fluency task as being reflective of aging effect. Geriatrics and Gerontology International, 15(4), 496-500.

Korean Educational Development Institute. (2002). Study on Illiteracy of Korean Elderly. Seoul: Korean Education Development Institute.

Kuo, H. K., Jones, R. N., Milberg, W. P., Tennstedt, S., Talbot, L., Morris, J. N., et al. (2005). Effect of blood pressure and diabetes mellitus on cognitive and physical functions in older adults: A longitudinal analysis of the advanced cognitive training for independent and vital elderly cohort. Journal of the American Geriatrics Society, 53(7), 1154-1161.

Longstaff, M. G. \& Heath, R. A. (1997). Space-time invariance in adult handwriting. Acta Psychologica, 97(2), 201-214.

MacKay, A. \& Connor, L. T. (2001). Proceedings of the 29th International Neuropsychological Society: Detecting Age-Related Change in Naming: Item Analysis of the Boston Naming Test. Chicago, IL.

Mark, L. (2009). Health literacy and the elderly. Osteopathic Family Physician, 1(3), 64-69.

Torrance, M., van Waes, L., \& Galbraith, D. (2007). Writing and Cognition: Research and Applications. Amsterdam: Elsevier.

Peltzer, K. \& Phaswana-Mafuya, N. (2012). Cognitive functioning and as- sociated factors in older adults in South Africa. South African Journal of Psychiatry, 18(4), 157-163.

Proust-Lima, C., Amieva, H., Letenneur, L., Orgogozo, J. M., JacqminGadda, H., \& Dartigues, J. F. (2008). Gender and education impact on brain aging: A general cognitive factor approach. Psychology and Aging, 23(3), 608-620.

Randolph, C., Lansing, A. E., Ivnik, R. J., Cullum, C. M., \& Hermann, B. P. (1999). Determinants of confrontation naming performance. Archives of Clinical Neuropsychology, 14(6), 489-496.

Raz, N., Rodrigue, K. M., \& Acker, J. D. (2003). Hypertension and the brain: Vulnerability of the prefrontal regions and executive functions. Behavioral Neuroscience, 117(6), 1169-1180.

Rodríguez-Aranda, C. \& Sundet, K. (2006). The frontal hypothesis of cognitive aging: Factor structure and age effects on four frontal tests among healthy individuals. The Journal of Genetic Psychology, 167(3), 269-287.

Schneider, B. C. \& Lichtenberg, P. A. (2011). Influence of reading ability on neuropsychological performance in African American elders. Archives of Clinical Neuropsychology, 26(7), 624-631.

Seeman, T. E., Lusignolo, T. M., Albert, M., \& Berkman, L. (2001). Social relationships, social support, and patterns of cognitive aging in healthy, high-functioning older adults: MacArthur studies of successful aging. Health Psychology, 20(4), 243-255.

Statistics of Korea. (2012). Statistics of the Elderly. Seoul: Statistics of Korea.

World Health Organization. (2001). International Classification of Functioning, Disability and Health. Geneva: World Health Organization. 